Final Scientific/Technical Report

\title{
PROJECT TITLE: AMBIENT LABORATORY COATER FOR ADVANCED GAS REACTOR FUEL DEVELOPMENT
}

AWARD NUMBER: ID14659

AWARDEE NAME: University of Tennessee, Knoxville

Principal Investigators: Duane D. Bruns and Robert M. Counce

Student Investigator: Irma D. Lima Rojas

Collaborating Investigators : Ke Nguyen, S. C. Daw, C. E. A. Finney, Trewei Wang

Period covered: Mar 17, 2005 - Mar 16, 2010 



\title{
Results for the investigation of hydrodynamic scaling relationships in shallow spouted beds
}

\author{
Irma D. Lima Rojas
}

\section{Department of Chemical \& Biomolecular Engineering, University of Tennessee, Knoxville, TN,}

\section{USA}

This report is very similar to the manuscript, which will be published in the journal Separation Science and Technology in September 2010 by Irma D. Lima Rojas, D.B. Bruns, C. S. Daw, K. Nguyen and C.E.A. Finney, Preliminary results for the investigation of hydrodynamic scaling relationships in shallow spouted beds.

Abstract: This research is targeted at developing improved experimentally-based scaling relationships for the hydrodynamics of shallow, gas-spouted beds of dense particles. The work is motivated by the need to more effectively scale up shallow spouted beds used in processes such as in the coating of nuclear fuel particles where precise control of solids and gas circulation is critically important.

Experimental results reported here are for a $50 \mathrm{~mm}$ diameter spouted bed containing two different types of bed solids (alumina and zirconia) at different static bed depths and fluidized by air and helium. Measurements of multiple local average pressures, inlet gas pressure fluctuations, and spout height were used to characterize the bed hydrodynamics for each operating condition. Follow-on studies are planned that include additional variations in bed size, particle properties, and fluidizing gas. The ultimate objective is to identify the most important non-dimensional hydrodynamic scaling groups and possible spouted-bed design correlations based on these groups.

The minimum spouting velocity for a fixed, shallow spouted bed operating with dense particles was found to increase with increasing static bed height, particle diameter and particle density, and also with decreasing fluidizing gas density. A preliminary analysis indicates that all of these effects can be correlated with simple function relating the particle Reynolds number at minimum spouting condition to dimensionless forms of the particle diameter and bed height and the Archimedes number. 
It was also found that overall pressure drop increases with increasing static bed height and particle density and with decreasing particle diameter and fluidizing gas density. Simple functional forms relating dimensionless pressure drop to the Archimedes number or the minimum spouting particle Reynolds number and dimensionless particle diameter and static bed height were found to give good fits to the present experimental data.

The trends of fountain height observed here were more complex that the trends in minimum spouting velocity and pressure drop. The results obtained in this study indicate that the fountain height increases with increasing gas flow rate, gas density, particle diameter and static bed height and decreasing particle density. The effect of the temperature on the fluidization gas is simulated using different gases (air and helium); the result obtained in this study indicate that the fountain height decreases as the temperature of the fluidizing gas increases, which is reflected in a reduction of the drag force. This study revealed that the static bed height, particle density and the gas flow rate are the most important interacting factors that have a major effect to the fountain height.

As noted above, this was a preliminary part of a larger investigation involving additional spouted bed parametric variations. Thus all of the above conclusions and observations need to be considered as provisional until the additional experiments are completed.

Keywords: shallow spouted beds, hydrodynamic relationships, fluidized beds, scaling groups, scaling spouted beds 


\section{INTRODUCTION}

Spouted beds are widely used for gas-solids contacting where high solids circulation is important. Typically, spouted beds have a central gas jet that entrains solids near the bottom of the bed and transports them upward through a central zone toward the top. As the upward-moving solid particles exit the top of the bed and separate from the gas, they fall back to the bed surface and move slowly downward in an outer annular zone toward the bottom [1]. The net effect of these two opposing solids flows is to create a toroidal-like circulation cell that defines the overall solids circulation. The interface between the upward and downward moving solids is not rigid but can vary in space and time. In some cases a cylindrical draft tube is inserted in the center of the bed to stabilize the interface $[2,3]$. This enhances the separation between the upward and downward flow zones and increases the overall circulation rate.

Industrial applications of spouted beds include combustion, coating, drying, and gasification [4-6]. There are at least four widely used spouted-bed configurations: flat-base cylindrical, conical-base cylindrical, conical and dilute jet. $\mathrm{Bi}$ [7] reviews many of the salient differences among these designs. In the majority of applications in conical-base beds, the solids bed height in the cylindrical section is deeper than the height of the conical bottom [8]; this is termed a "deep bed".

For many types of unit operations, proper scaling is critical in relating laboratory studies to full-scale production. This is also true for spouted beds, where it is desirable to conduct laboratory studies at ambient conditions that are relevant to commercial units operating at elevated pressure and temperature. However, scaling up a process involves more than the useful laboratory studies; it requires that some parameters for the larger beds preserve the same values of the small one, which in turn provokes uncertainty on scale-up criteria. The basic groundwork for scaling in fluidized beds in 
general (which includes spouted beds as a subset) has been discussed in numerous previous studies, most notably in the pioneering work of Glicksman $[9,10]$. However, scaling of spouted beds still remains a relatively undeveloped area.

To address scaling, it is first necessary to identify the key non-dimensional groups that control the hydrodynamics. In the approach of Glicksman [11,12], Horio [13] and others, the principal dimensionless groups underlying the fluidized-bed hydrodynamics are identified by nondimensionalizing the appropriate momentum and mass conservation equations for the gas and solids. As a result of his analysis, Glicksman [11] determined that the appropriate dimensionless groups defining the hydrodynamics of fluidized beds are $\frac{g d_{p}}{U^{2}}, \frac{\rho_{s} d_{p} U}{\mu_{g}}, \frac{\rho_{g}}{\rho_{s}}, \frac{H_{0}}{d_{p}}, \frac{D_{c}}{d_{p}}, \frac{L_{1}}{L_{2}}, D P S D, \phi_{s}$, where $g$ is gravitational acceleration, $d_{p}$ is particle diameter, $U$ is superficial gas velocity, $\rho_{s}$ is the solids density, $\rho_{g}$ is the gas density, $H_{0}$ is the static bed depth, $D_{c}$ is the bed cylinder diameter, $L_{1}$ and $L_{2}$ are characteristic length scales, DPSD is the dimensionless particle size distribution, and $\phi_{\mathrm{s}}$ is the solids sphericity.

In more recent work, He et al. [14], from considering mechanical effects in the annulus zone, proposed two additional dimensionless numbers: the internal friction angle, $\phi$, and the loose-packed voidage, $\varepsilon_{0}$. They experimentally validated their predictions on the basis of measurements of maximum spoutable bed depth, spout diameter, fountain height, and pressure profiles in the annulus as functions of static bed height.

Still more recently, Xu et al. [15] added the particle-particle coefficient of restitution $\left(\mathrm{e}_{s s}\right)$ to the scaling relationships of spouted beds proposed by He et al. This parameter was included based on their analysis of the kinetic energy of colliding particles in the spout and annulus regions. Their conclusions seem to 
be supported by Goldschmidt et al. [16], who also claimed that the flow dynamics of gas-solids systems, such as the bed expansion ratio, are sensitive to $e_{s s}$. Xu et al. [15] experimentally validated their predictions on the basis of measurements of fountain height, spout diameter, and voidage profiles with changing coefficients of restitution.

Considering the above, the complete list of key dimensionless groups to consider in spouted bed scaling should include: $\frac{g d_{p}}{U^{2}}, \frac{\rho_{s} d_{p} U}{\mu_{g}}, \frac{\rho_{g}}{\rho_{s}}, \frac{H_{0}}{d_{p}}, \frac{D_{c}}{d_{p}}, \frac{L_{1}}{L_{2}}, D P S D, \phi_{s}, \varphi, \varepsilon_{o}, e_{s s}$, This list of dimensionless groups is by no means exhaustive. One would also expect that geometric ratios associated with bed shape and configuration would be important for scaling, as they are needed to define the boundary conditions for the continuity and momentum equations. Finally, it should be noted that the combination of the size distribution and shape of actual particles cannot be captured in the single-value descriptors used in these dimensionless groups. As yet, rigorous ways to include this variability aspect in dimensionless terms have not been defined.

Given the above key scaling groups, it should be theoretically possible to accurately scale from any spouted bed to any other, as long as the same values are maintained for each of the groups. In practice however, it is virtually impossible to match all of the groups simultaneously on two different beds, thus one is typically constrained to focus on recognizing the most important groups in a particular context and matching those as much as possible. Such reduced-order scaling can still be effective as long as the local hydrodynamic features are dominated by the accessible subset of dimensionless groups. The difficulty of experimentally controlling all of the dimensionless groups simultaneously is also why only a subset of the above dimensionless groups (or a rearrangement of a subset) is typically included in experimentally derived correlations [17-22]. Once the range of conditions utilized to derive correlations 
is exceeded (i.e., one uses them to extrapolate), the potential accuracy of predictions can be decreased considerably. Such losses of accuracy should not be surprising since the relative importance of the missing dimensionless groups can increase considerably outside the experimental limits. Furthermore, the fact that scaling fluidized or spouted beds commonly require some fixed parameters such as materials nature and shape justifies the lack of some unimportant dimensionless groups on the scaling and hydrodynamic predictions.

As noted previously, the correlations in the spouted-bed literature are dominated by deep beds of particles with densities of less than $3000 \mathrm{~kg} / \mathrm{m}^{3}$. The only correlations relevant to the shallow, dense category are those developed by Zhou [19], who focused his study on defining the hydrodynamics of shallow beds similar to those beds used to coat TRISO fuel particles but at ambient temperature, using $\mathrm{ZrO}_{2}$ (yttrium-stabilized zirconia, or YSZ, with a material density of $6100 \mathrm{~kg} / \mathrm{m}^{3}$ ) as surrogate fuel particles. Zhou determined the effect of the cone angle, static height and particle size over the minimum spouting velocity, overall pressure drop and fountain height. Thus the focus of this study will be on expanding the earlier work of Zhou to include more of the key dimensionless groups and increase the range for accurate scaling predictions, especially scaling predictions involving changes in bed size, inlet diameter, particle density, gas viscosity, and gas density. Bed size and gas properties are included because they directly relate to scaling from small, ambient laboratory experiments to production-scale beds. 


\section{EXPERIMENTAL}

\section{Apparatus}

A schematic of the experimental setup is shown in Figure 1. The spouted bed used in these experiments was fabricated from a $150 \mathrm{~mm}$ long quartz tube fitted at the bottom with a $60^{\circ}$ included angle aluminum cone. The bottom cone had a height equal to the diameter of the cylinder. A leveler located right below the cone was used to insure fully vertical orientation. At the end of each experiment, the solid particles were drained to a collector jar via a discharge valve.

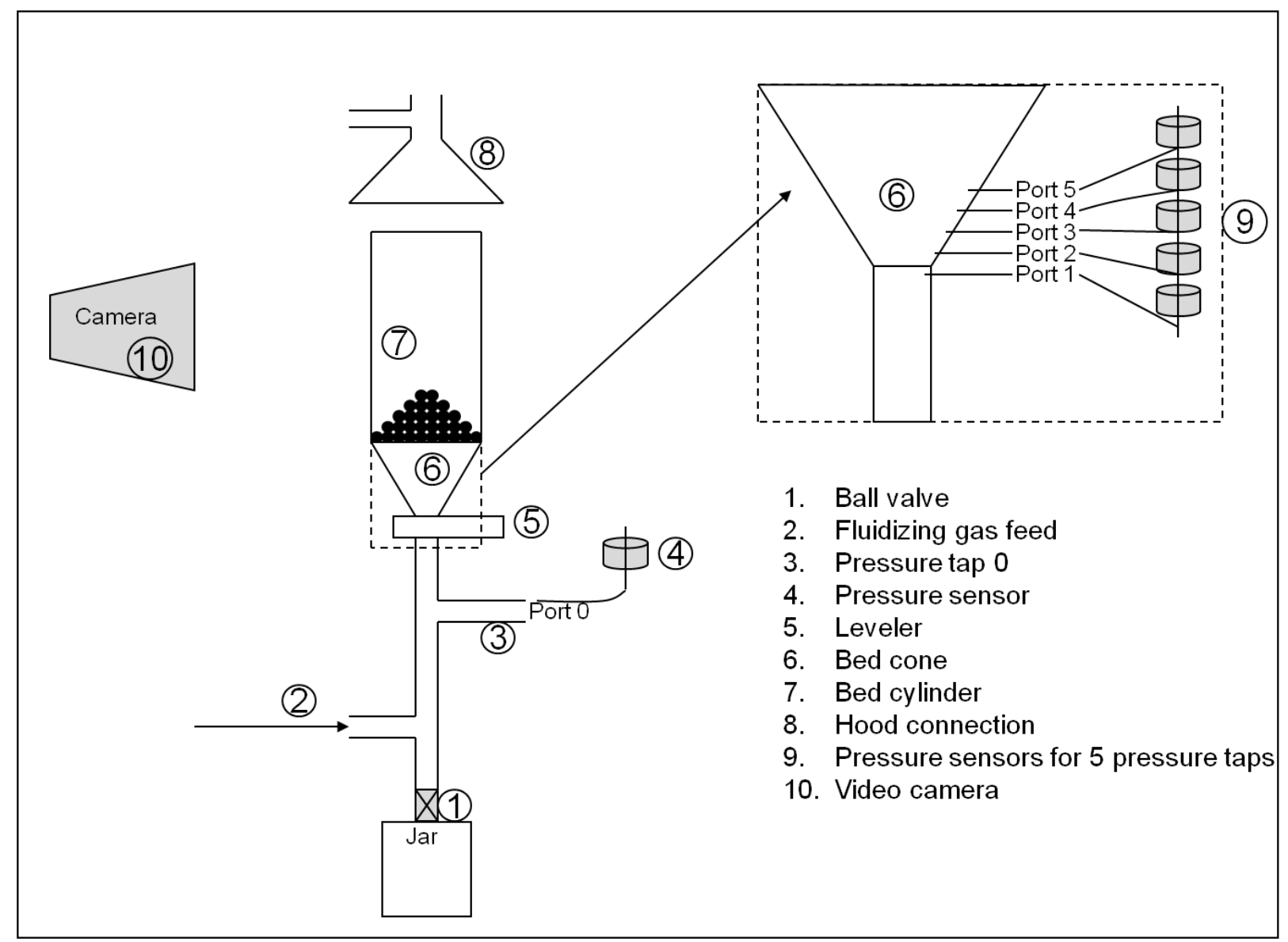

Figure 1. Schematic of the experimental apparatus 
The $50 \mathrm{~mm}$ spouted bed has 6 pressure taps. The first pressure tap, designated as Port 0 and located approximately 10 diameters of the cone inlet upstream from the base of the aluminum cone, was used to measure average and dynamical global pressure drops. From the average global pressure the minimum spouting velocity $\left(U_{m s}\right)$ was determined by monitoring the global pressure drop as gas flow was reduced from a fully spouting condition to a nearly packed bed. The minimum spouting velocity was defined as the flow where the pressure drop abruptly increased (as shown in Figure 2).

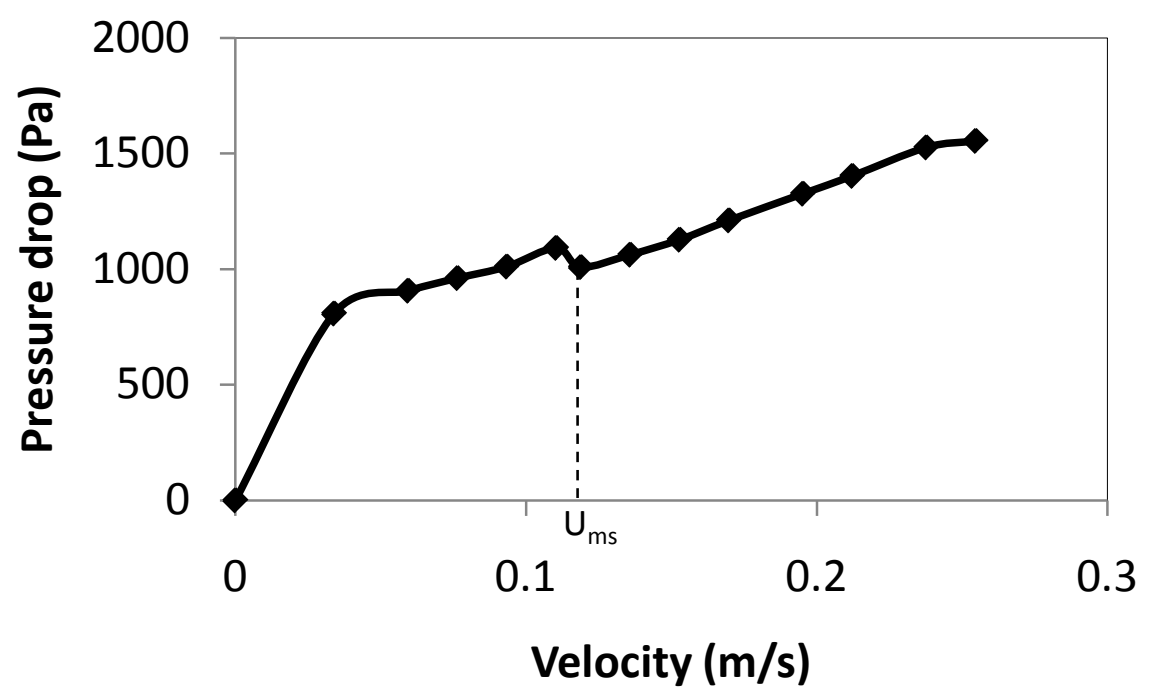

Figure 2. Determination of $\mathrm{U}_{\mathrm{ms}}$ on the $50 \mathrm{~mm}$ bed for $75 \mathrm{~g}$ of $500 \mu \mathrm{m}$ of $\mathrm{ZrO}_{2}$ particles.

Of the remaining five pressure taps (local pressure drops), four were located on the side of the cone at 2, 4, 8 and $16 \mathrm{~mm}$ measured from the base of the cone, and one $2 \mathrm{~mm}$ below the base of the cone. All six taps were connected to pressure transducers. Depending on the dynamic pressure range, taps were connected to either single-sided Endevco 8510B-1 transducers or to MKS Baratron 223B-type differential pressure transducers with different full-scale ranges. 
Gas flow was controlled using 1559A, 1579A and 1179A MKS mass flow controllers and was humidified to approximately $40 \%$ relative humidity in a countercurrent humidification chamber to minimize static charge buildup. The experimental particles were 500 and $1000 \mu \mathrm{m}$ diameter sizes of alumina (4000 $\mathrm{kg} / \mathrm{m}^{3}$ ) and yttrium-stabilized zirconia $\left(6100 \mathrm{~kg} / \mathrm{m}^{3}\right)$. Static bed heights were $42 \%$ and $67 \%$ of the cylinder diameter and gas flow rates ranged from about 1.2 to $2.1 \mathrm{U} / \mathrm{U}_{\mathrm{ms}}$, respectively. Particle densities were determined from the water displacement method. Helium and air fluidizing gases are used to simulate the effect of temperature on the bed hydrodynamic behavior. The effect of the DPSD, $\Phi_{s}, \varepsilon_{0}$ and $e_{s s}$ on the hydrodynamics behavior is not considered on this study, as particle properties, in a practical sense, are not expected to change with reactor size.

At each selected operating condition, the mean and transient pressures at each of the six wall pressure taps and the time-averaged fountain height were measured to characterize the hydrodynamic state. All six pressure signals were recorded at a sampling rate of $1000 \mathrm{~Hz}$ for duration of one minute. From the unfiltered transient pressure signals the mean pressure drops at different locations were determined by averaging. The dynamic pressure signals were also low-pass filtered at $100 \mathrm{~Hz}$ and then characterized in terms of their frequency content and time-series statistics for diagnostics purposes. A consumer-grade video camera (Sony) was used to record the fountain fluctuations at 30 frames per second for segments of over one minute at each condition, simultaneously with the pressure measurements. The average fountain height is obtained by creating a composite image (see Figure 3) from a set of 30 randomly selected frames from one-minute video recordings and then using image analysis to determine the mean fountain height as illustrated in Figure 4. 


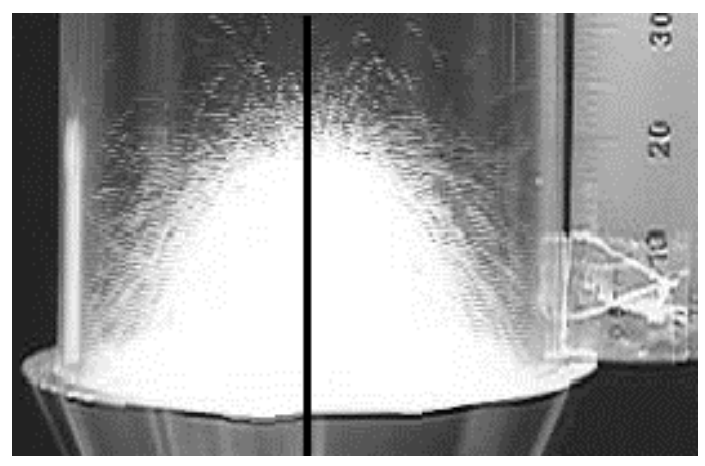

Figure 3. Composite image at $1.65 \mathrm{U} / \mathrm{U}_{\mathrm{ms}}$, with $0.67 \mathrm{H}_{0} / \mathrm{D}_{\mathrm{c}}$ of $500 \mu \mathrm{m} \mathrm{ZrO}$ particles.

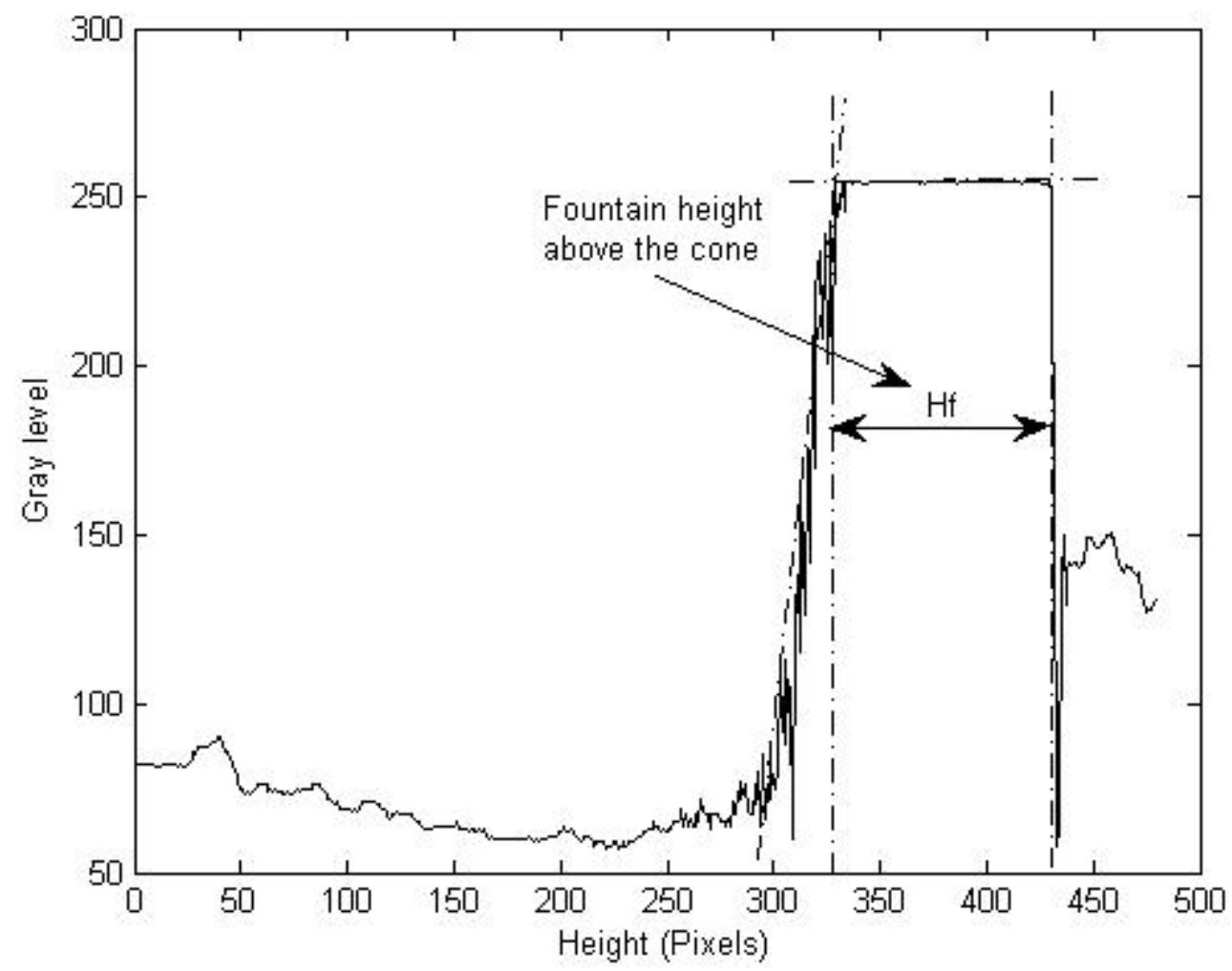

Figure 4. Diagram illustrating the procedure for fountain height $\left(\mathrm{H}_{\mathrm{f}}\right)$ measurement at 1.65 $\mathrm{U} / \mathrm{U}_{\mathrm{ms}}$, with $0.67 \mathrm{H}_{0} / \mathrm{D}_{\mathrm{c}}$ of $500 \mu \mathrm{m} \mathrm{ZrO}$ particles. The vertical axis indicates the gray-scale intensity determined from a pixel-by-pixel analysis along the centerline of the composite digital image.

\section{RESULTS AND DISCUSSION}




\section{Minimum spouting velocity}

Table 1 includes a list of the minimum spouting velocity $\left(U_{m s}\right)$ and overall pressure drop $(\Delta P)$ obtained for different combinations of the operating parameters in the $50 \mathrm{~mm}$ bed. It can be observed that $\mathrm{U}_{\mathrm{ms}}$ increases with increasing static bed height, particle diameter and particle density, and decreasing fluidizing gas density. Based on these experimental observations, an analysis of variance revealed that the most significant dimensionless factors for defining $U_{\mathrm{ms}}$ are $\frac{H_{0}}{D_{c}}, \frac{d_{p}}{D_{c}}, \operatorname{Ar}$ and $\operatorname{Re}_{\mathrm{ms}}$, where $\operatorname{Ar}$ is the Archimedes number and $\mathrm{Re}_{\mathrm{ms}}$ is the Reynolds number at minimum-spouting conditions.

Table 1: $U_{m s}$ values at different particle size, particle density, static height and gas density for the 50 $\mathrm{mm}$ spouted bed

\begin{tabular}{ccccccccc}
\cline { 3 - 8 } & & \multicolumn{2}{c}{ Air } & \multicolumn{2}{c}{ Helium } & \multicolumn{2}{c}{ Air-Helium difference } \\
\hline $\begin{array}{c}\text { Particle } \\
\text { material }\end{array}$ & $\begin{array}{c}\text { Particle size } \\
(\boldsymbol{\mu m})\end{array}$ & $\mathbf{H}_{\mathbf{0}} / \mathbf{D}_{\mathbf{c}}$ & $\begin{array}{c}\mathbf{U}_{\mathbf{m s}} \\
(\mathbf{m} / \mathbf{s})\end{array}$ & $\begin{array}{c}\Delta \mathbf{P} \\
(\mathbf{P a})\end{array}$ & $\begin{array}{c}\mathbf{U}_{\mathbf{m s}} \\
(\mathbf{m} / \mathbf{s})\end{array}$ & $\begin{array}{c}\Delta \mathbf{P} \\
(\mathbf{P a})\end{array}$ & $\begin{array}{c}\mathbf{U}_{\mathbf{m s}} \\
(\mathbf{\%})\end{array}$ & $\begin{array}{c}\boldsymbol{\Delta} \mathbf{P} \\
(\%)\end{array}$ \\
\hline $\mathrm{Al}_{2} \mathrm{O}_{3}$ & 500 & 0.42 & 0.06 & 408.0 & 0.09 & 453.3 & 45.4 & 11.1 \\
$\mathrm{Al}_{2} \mathrm{O}_{3}$ & 500 & 0.75 & 0.11 & 604.2 & 0.14 & 690.4 & 23.0 & 14.3 \\
$\mathrm{Al}_{2} \mathrm{O}_{3}$ & 1000 & 0.42 & 0.16 & 340.0 & 0.27 & 395.4 & 68.3 & 16.3 \\
$\mathrm{Al}_{2} \mathrm{O}_{3}$ & 1000 & 0.67 & 0.29 & 486.8 & 0.49 & 576.1 & 71.1 & 18.4 \\
$\mathrm{ZrO}_{2}$ & 500 & 0.42 & 0.06 & 590.4 & 0.12 & 665.6 & 96.5 & 12.8 \\
$\mathrm{ZrO}_{2}$ & 500 & 0.67 & 0.12 & 880.7 & 0.18 & 1033.8 & 50.6 & 17.4 \\
$\mathrm{ZrO}_{2}$ & 1000 & 0.42 & 0.20 & 498.9 & 0.30 & 581.9 & 45.4 & 16.7 \\
$\mathrm{ZrO}_{2}$ & 1000 & 0.67 & 0.34 & 759.1 & 0.56 & 898.0 & 63.6 & 18.3 \\
\hline
\end{tabular}

A regression analysis based on the results depicted in Table 1 suggested the following type of correlation:

$\operatorname{Re}_{m s}=0.5\left(\frac{H_{0}}{D_{c}}\right)^{1.166}\left(\frac{d_{p}}{D_{c}}\right)^{0.79} A r^{0.59}$ 
Figure 5 compares the predictions of this correlation with the experimental $U_{m s}$ values. The regression coefficient is 0.98 .

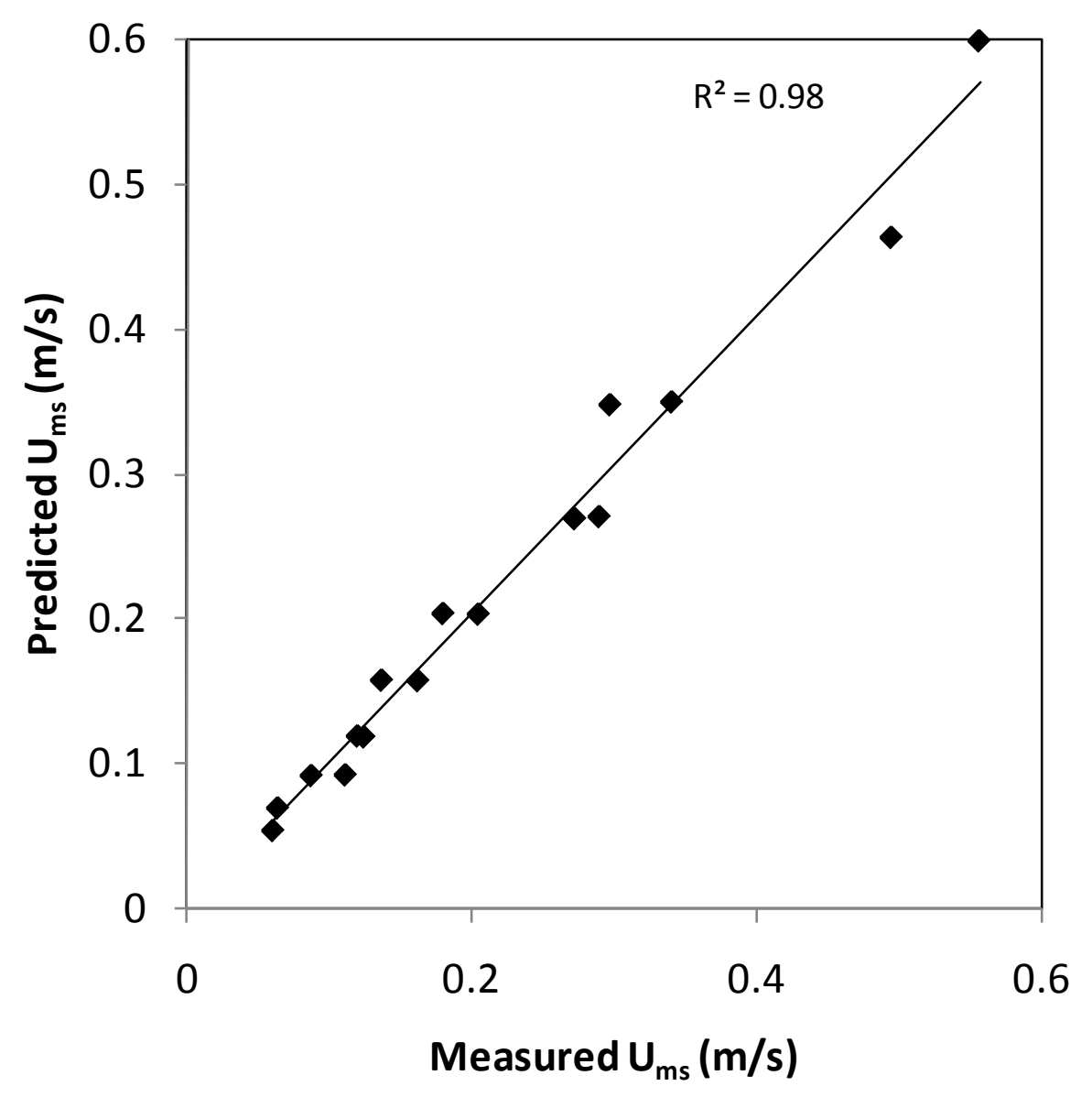

Figure 5. Predicted $\mathrm{U}_{\mathrm{ms}}$ vs measured $\mathrm{U}_{\mathrm{ms}}$. 


\section{Pressure drop}

The focus of this discussion is on the time-average pressure drop measured from the lowest pressure tap (Port 0). Fig. 6 illustrates an interesting difference in the spouted-bed behavior with air versus helium fluidization. With air, the pressure drop across the bed was nearly constant while fluidizing particles up to $U / U_{m s}=2$. However for helium, the pressure is not constant after $U / U_{m s}=1.8$ but begins to rise slowly with flow. Visually, the spouting regime with helium also appeared to be highly unstable and unsteady at the higher flow rates, resulting in a higher pressure-signal variance. Also, it can be observed that the pressure drop across the bed for helium as fluidizing gas is larger than for air. All of the above changes reflect important changes in the spouting hydrodynamics related to the lower gas viscosity and density of helium relative to air.

At very low gas flows there were also important differences between air and helium fluidization. The different gas properties appeared to affect the packing and flow behavior of the particles at near the gas inlet. With air, pressure drop reached a maximum value, and then started to rapidly decrease until the particles began to fall into the gas inlet tube. With helium, the particles began to collect more smoothly near the inlet tube at higher flows.

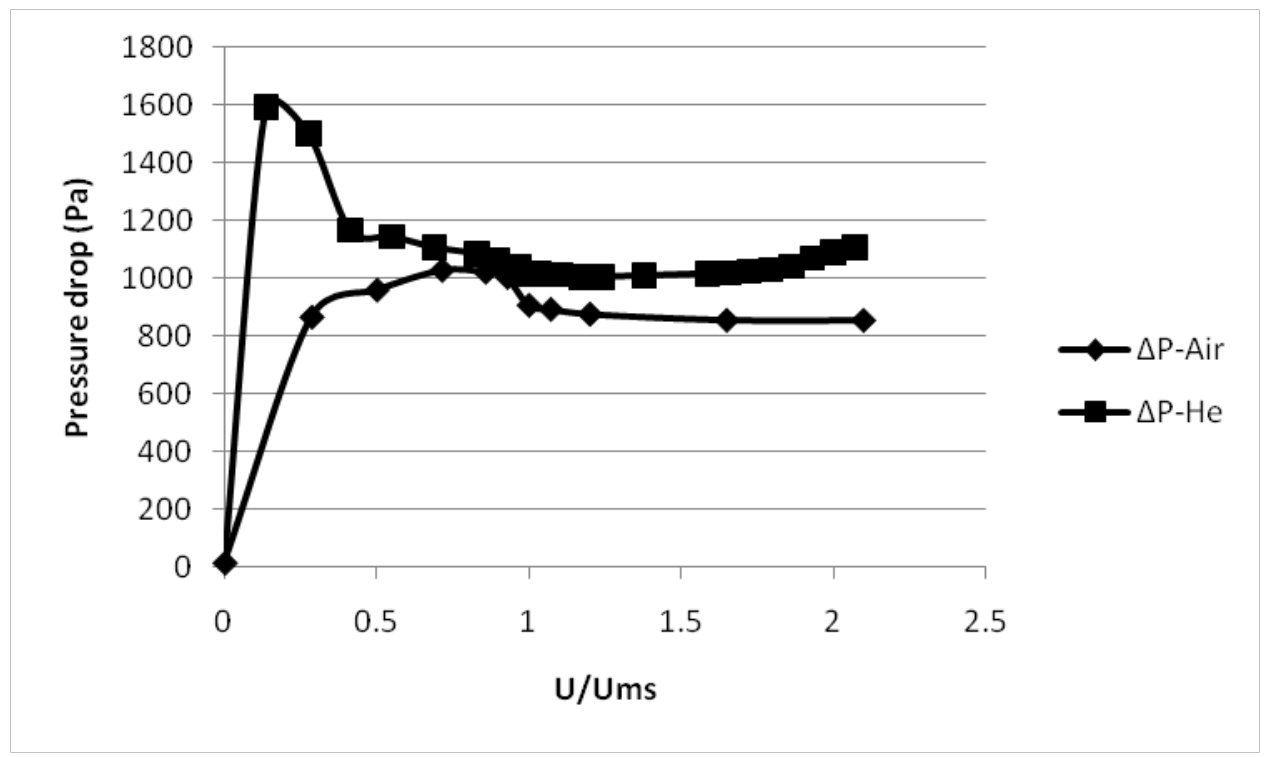


Figure 6. Average pressure drop at Port 0 of the $50 \mathrm{~mm}$ diameter spouted bed as a function of $\mathrm{U} / \mathrm{U}_{\mathrm{ms}}$ for



Preliminary data analysis revealed that the most significant dimensionless factor for correlating the pressure drop at minimum spouting $\left(\Delta \mathrm{P}_{\mathrm{s}}\right)$ is the Archimedes number (Ar). From the data listed in Table 1, two correlations were fit by regression; the coefficients of regression are 0.92 and 0.97 for Eq. 2 and 3 respectively (see Fig. 7 ).

$$
\frac{\Delta P_{s}}{\rho_{s} H_{0} g}=1.087(A r)^{-0.081}
$$

Another form of $\Delta \mathrm{P}_{\mathrm{s}}$ in terms of $\mathrm{Re}_{\mathrm{ms}}$ is given by Eq. 3:

$$
\frac{\Delta P_{s}}{\rho_{s} H_{0} g}=1.01\left(\mathrm{Re}_{m s}\right)^{-0.132}\left(\frac{H_{0}}{D_{c}}\right)^{0.022}\left(\frac{d_{p}}{D_{c}}\right)^{0.1}
$$



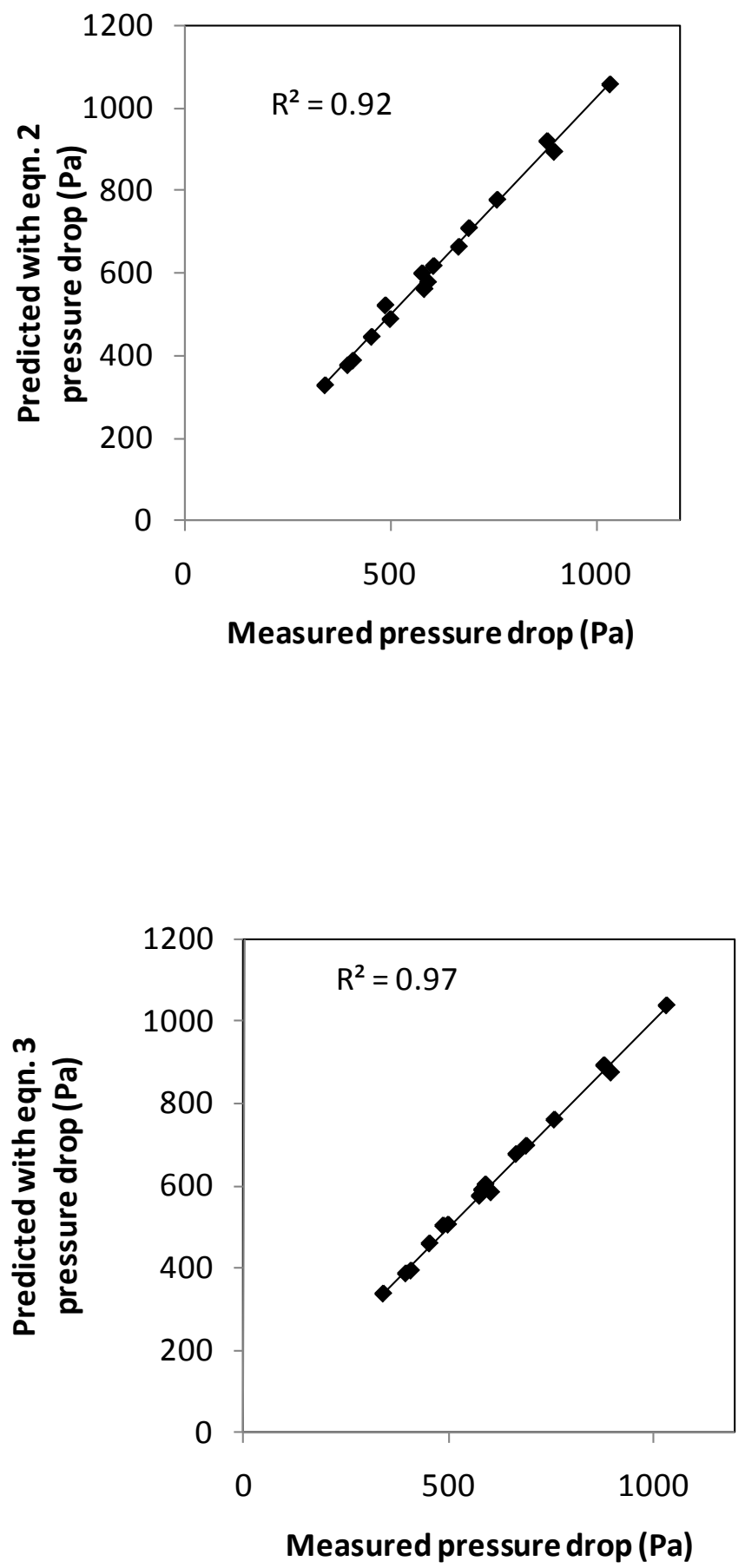

Figure 7. Predicted $\Delta \mathrm{P}$ vs measured $\Delta \mathrm{P}$ 


\section{Fountain height}

At gas flows below $2.1 \mathrm{U} / \mathrm{U}_{\mathrm{ms}}$, the time-average fountain height appears to vary linearly with gas flow for all cases listed in Table 1 (see Figs. 8 and 9), beyond which the estimate of time-average fountain height is less certain due to larger fluctuations of the fountain height. Also noteworthy is how the linear trends for 500 and $1000 \mu \mathrm{m}$ particle diameters overlap between 1.2 and $1.6 \mathrm{U} / \mathrm{U}_{\mathrm{ms}}$ for $\mathrm{Al}_{2} \mathrm{O}_{3}$; for $\mathrm{ZrO}_{2}$, the linear trends overlap just between 1.2 and $1.4 \mathrm{U} / \mathrm{U}_{\mathrm{ms}}$. On the other hand, it can be seen that the static bed height, particle density and the gas flow rate are important interacting factors that have a major effect on the fountain height.



Figure 8. Effect of gas flow rate on fountain height of $50 \mathrm{~mm}$ diameter spouted bed for different sizes of $\mathrm{ZrO}_{2}$ and $\mathrm{Al}_{2} \mathrm{O}_{3}$ at $0.75 \mathrm{H}_{0} / \mathrm{D}_{\mathrm{c}}$ 


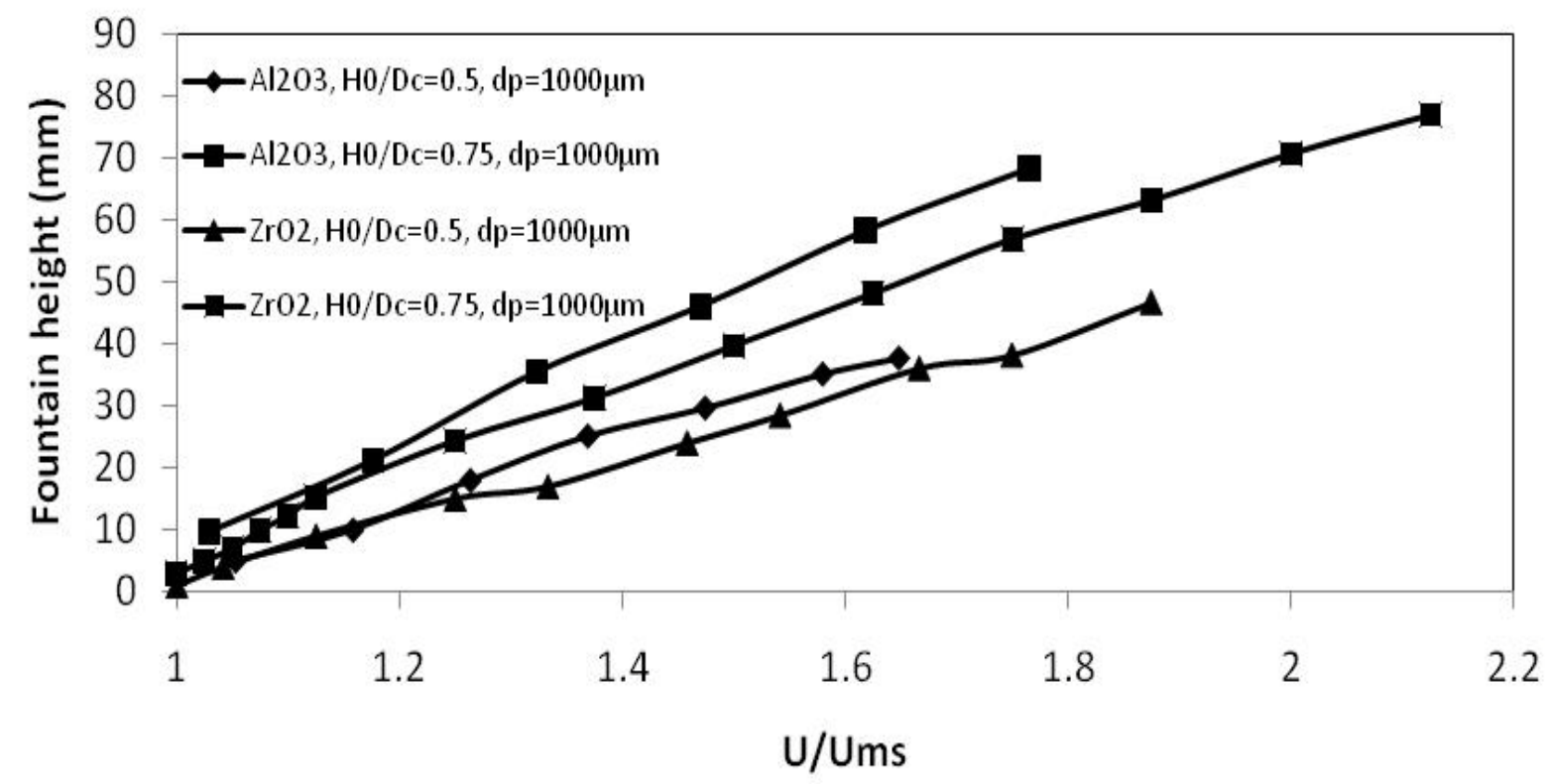

Figure 9. Fountain height as a function of $\mathrm{U} / \mathrm{U}_{\mathrm{ms}}$ measured on the $50 \mathrm{~mm}$ diameter spouted bed with $\mathrm{H}_{0} / \mathrm{D}_{\mathrm{c}}=0.75$ and 0.5 with $1000 \mu \mathrm{m} \mathrm{ZrO}_{2}$ and $\mathrm{Al}_{2} \mathrm{O}_{3}$ particles. 
The most significant dimensionless factor for correlating the fountain height are $\frac{H_{f}}{H_{0}}, \frac{U}{U_{m s}}, \frac{H_{0}}{D_{c}}, \frac{d_{p}}{D_{c}}, \operatorname{Ar}$ and $\mathrm{Re}_{\mathrm{ms}}$. From the measurements of fountain height done to the listed cases in Table 1 at $1.65 \mathrm{U} / \mathrm{U}_{\mathrm{ms}}$ and $1.2 \mathrm{U} / \mathrm{U}_{\mathrm{ms}}$, a correlation was fit by regression with a coefficient of regression of 0.90 (see Fig. 8 ).

$\frac{H_{f}}{H_{0}}=0.33\left(\frac{U}{U_{m s}}\right)^{2.95}\left(\frac{d_{p}}{D_{c}}\right)^{-2.96}\left(\frac{H_{0}}{D_{c}}\right)^{-4.05}(A r)^{-1.95}(\mathrm{Re})^{3.57}$

Eq. 4

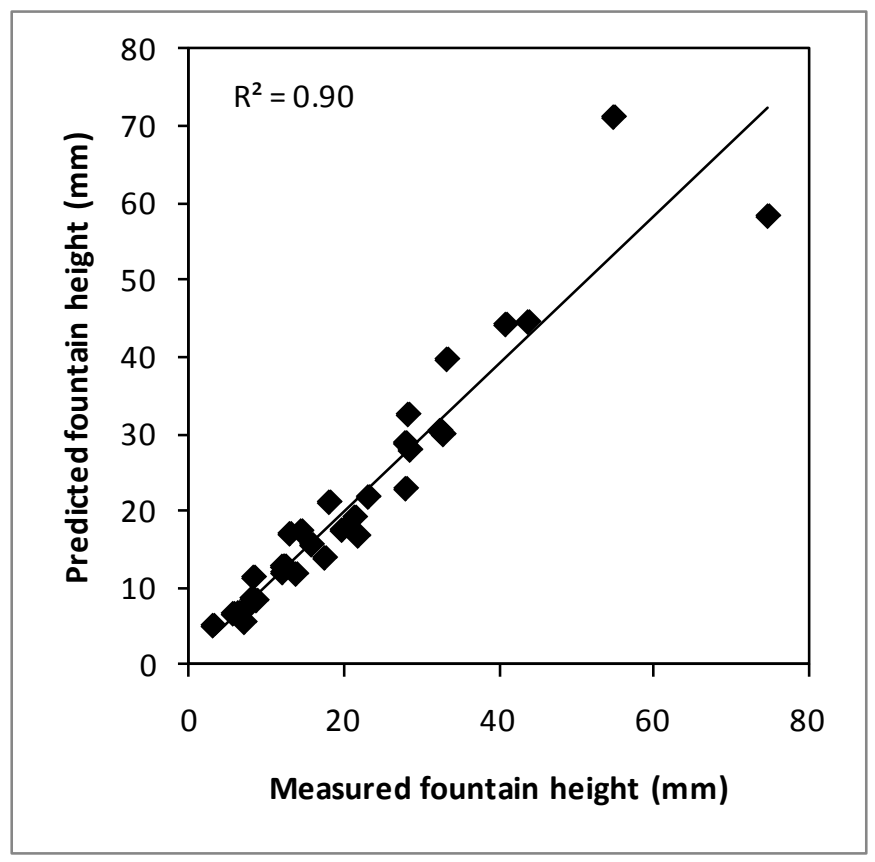

Figure 8. Predicted $\mathrm{H}_{\mathrm{f}}$ vs measured $\mathrm{H}_{\mathrm{f}}$ 


\section{CONCLUSIONS}

Minimum spouting velocity for a fixed, shallow spouted bed operating with dense particles was found to increase with increasing static bed height, particle diameter and particle density, and also with decreasing fluidizing gas density. A preliminary analysis indicates that all of these effects can be correlated with simple function relating the particle Reynolds number at minimum spouting condition to dimensionless forms of the particle diameter and bed height and the Archimedes number. This seems to be generally consistent with the results of Mathur and Gishler [18], although not all of the parameters they considered were included in this preliminary study. This study extends this trend to shallower beds and denser particles than have been previously reported.

It was found that overall pressure drop increases with increasing static bed height and particle density and with decreasing particle diameter and fluidizing gas density. According to other authors such as Mukhlevov and Gorshtein [23] and Olazar [20], the pressure drop decreases as $\mathrm{Re}_{\mathrm{ms}}$ increases, and increases as $\mathrm{H}_{0}$ and $\mathrm{Ar}$ increase. Simple functional forms relating dimensionless pressure drop to the Archimedes number or the minimum spouting particle Reynolds number and dimensionless particle diameter and static bed height were found to give good fits to the present experimental data.

The trends of fountain height observed here were more complex that the trends in minimum spouting velocity and pressure drop. Other studies such as those by Grace and Mathur [25], Day [26], San José et al. [27], and Zhou [24] found that the larger the larger the cone inlet diameter, $U / \cup_{m s}$, and $\varepsilon_{0}$, the larger the $H_{f}$; also, the larger $\rho_{s}$, the smaller $H_{f}$. However the effect of static bed height appear to be contradictory. The result obtained in this study specifies that $\mathrm{H}_{\mathrm{f}}$ increases with increasing gas flow rate, gas density, particle diameter and static bed height and decreasing particle density. The effect of the 
temperature on the fluidization gas is simulated using different gases (air and helium), and the result obtained in this study revealed the same as Wu et al.[28], who reported that the fountain height decreases as the temperature of the fluidizing gas increases, which is reflected in a reduction of the drag force. This study revealed that the static bed height, particle density and the gas flow rate are the most important interacting factors that have a major effect to the fountain height, which is in agreement to the empirical correlation of Grace and Mathur [25].

As noted above, this was a preliminary part of a larger investigation involving additional spouted bed parametric variations. Thus all of the above conclusions and observations need to be considered as provisional until the additional experiments are completed.

\section{ACKNOWLEDGEMENTS}

The author wishes to express her sincere appreciation to her present and former advisors at the University of Tennessee, Prof. Robert M. Counce and Prof. Duane D. Bruns, and her graduate committee members, Prof. Ke Nguyen, Prof. Tsewei Wang, Dr. C. Stuart Daw and Dr. Charles E.A. Finney for their continuing assistance in this research. Special thanks go to Prof. Bamin Khomami for his support. 


\section{NOMENCLATURE}

Ar $\quad$ Archimedes number $A r=\frac{d_{p}^{3} \rho_{g}\left(\rho_{p}-\rho_{g}\right) g}{\mu_{g}^{2}}$

$d_{p} \quad$ Particle diameter

$\mathrm{D}_{\mathrm{c}} \quad$ Bed cylinder diameter

DPSD Dimensionless particle size distribution

$\mathrm{e}_{\mathrm{ss}} \quad$ Particle-particle coefficient of restitution

$\mathrm{H}_{0} \quad$ Static particle bed height

$\mathrm{H}_{\mathrm{f}} \quad$ Fountain height

$\operatorname{Re}_{\mathrm{ms}} \quad$ Minimum spouting Reynolds number $\operatorname{Re}_{m s}=\frac{\rho_{p} d_{p} U_{m s}}{\mu_{g}}$

TRISO Tristructural-isotropic

$\mathrm{U}_{\mathrm{ms}} \quad$ Minimum spouting velocity

U Superficial gas velocity, based on bed cylinder

$\rho_{\mathrm{s}} \quad$ Solids density

Greek letters

$\rho_{\mathrm{g}} \quad$ Gas density

$\varepsilon_{0} \quad$ Loose packed voidage

$\varepsilon_{\mathrm{mf}} \quad$ Minimum fluidization voidage

$\phi_{s} \quad$ Particle sphericity

$\mu_{\mathrm{g}} \quad$ Gas viscosity

$\Delta \mathrm{P}_{\mathrm{s}} \quad$ Pressure drop across the particles inside the spouted bed 


\section{REFERENCES}

1. Kunii, D., Levenspiel, O. (1991) Fluidization Engineering, 2nd Ed. Butterworth-Heinemann: Boston

2. Zhao, X.-L., Yao Q., Li, S.-Q. (2006) Effects of draft tubes on particle velocity profiles in spouted beds. Chem. Eng. Tech., 29 (7): 875

3. Hattori, H., Ito, S., Onezawa, T., Yamada, K., Yanai, S. (2004) Fluid and solids flow affecting the solids circulation rate in spouted beds with a draft tube. J. Chem. Eng. Japan, 37 (9): 1085

4. Kutsakova, V.E. (2004) Drying of liquid and pasty products in a modified spouted bed of inert particles. Drying Tech., 22 (10): 2343

5. Abdul Salam, P., Bhattacharya, S.C. (2006) A comparative study of charcoal gasification in two types of spouted bed reactors. Energy, 31 (2-3): 228

6. Villa Briongos, J., Guardiola, J. (2005) New methodology for scaling hydrodynamic data from a 2D-fluidized bed. Chem. Eng. Sci., 60 (18): 5151

7. Bi, H.T. (2008) A discussion on minimum spout velocity and jet penetration length. Can. J. Chem. Eng., $82(1): 4$.

8. San José, M.J., Olazar, M., Aguado, R., Bilbao, J. (1996) Influence of the conical section geometry on the hydrodynamics of shallow spouted beds. Chem. Eng. J., 62 (2): 113

9. Glicksman, L.R. (1984) Scaling relationships for fluidized beds. Chem. Eng. Sci., 39 (9): 1373

10. Glicksman, L.R., Hyre, M., Woloshun, K. (1993) Simplified scaling relationships for fluidized beds. Powd. Tech., 77 (2): 177

11. Glicksman, L.R., Hyre, M.R., Farrell, P.A. (1994) Dynamic similarity in fluidization. Int. J. Multiphase Flow, 20 (1): 331

12. Glicksman, L.R. (1988) Scaling relationships for fluidized beds. Chem. Eng. Sci., 43 (6): 1419 
13. Horio, M., Nonaka, A., Sawa, Y., Muchi, I. (1986) A new similarity rule for fluidized bed scale-up. AIChE J. 32 (9): 1466

14. He, Y.-L., Lim, C.J., Grace, J.R. (1997) Scale-up studies of spouted beds. Chem. Eng. Sci., 52 (2): 329

15. Xu, J., Ji, Y., Wei, W., Bao, X., Du, W. (2007) Scaling relationships of gas-solid spouted beds. Fluidization XII, RP4 (65): 537

16. Goldschmidt, M.J.V., Kuipers, J.A.M., van Swaaij, W.P.M. (2001) Hydrodynamic modeling of dense gas-fluidized beds using the kinetic theory of granular flow: Effect of coefficient of restitution on bed dynamics. Chem. Eng. Sci., 56 (2): 571

17. Madonna, L.A., Lama, R.F (1958) The derivation of an equation for predicting minimum spouting velocity. AIChE J., 4 (4): 497

18. Mathur, K.B., Gishler, P.E. (1955) A technique for contacting gases with coarse solid particles. AIChE J., 1 (2): 157

19. Kmiec, A. (1983) The minimum spouting velocity in conical beds. Can. J. Chem. Eng., 61 (3): 274

20. Olazar, M., San José, M.J., Aguayo, A.T., Arandes, J.M., Bilbao, J. (1993) Pressure drop in conical spouted beds. Chem. Eng. J., 51 (1): 53

21. Wang, Z., Bi, H.T., Lim, C.J., Su, P. (2004) Determination of minimum spouting velocities in conical spouted beds. Can. J. Chem. Eng., 82 (1): 11

22. Fane, A.G., Mitchell, R.A. (1984) Minimum spouting velocity of scaled-up beds. Can. J. Chem. Eng., 62 (3): 437

23. Mukhlenov, I.P., Gorshtein, A.E. (1965) Investigation of a spouting bed. J. Khimicheskaya Promyhslennost, 41: 443 [cited in Ref. 24].

24. Zhou, J. (2008) Hydrodynamics and modeling of shallow spouted bed with high density particles. Ph.D. dissertation, University of Tennessee. 
25. Grace, J.R., Mathur, K.B. (1978) Height and structure of the fountain above spouted beds, Can. J. Chem. Eng., 56 (5): 533

26. Day, J.-Y. (1990) Fountain height and particle circulation rate in a spouted bed, Chem. Eng. Sci., 45 (9): 2987

27. San José, M.J., Olazar, M., Alvarez, S., Morales, A., Bilbao, J. (2005) Spout and fountain geometry in conical spouted beds consisting of solids of varying density. Ind. Eng. Chem. Res., 44 (1): 193

28. Wu, S.W., Lim, C.J., Epstein, N. (1987) Hydrodynamics of spouted beds at elevated temperatures, Chem. Eng. Commun., 62 (1): 261 